\title{
O ENSINO MÉDIO E AS COMPARAÇÕES INTERNACIONAIS: BRASIL, INGLATERRA E FINLÂNDIA*
}

\author{
Carmen Sylvia Vidigal Moraes ${ }^{1}$
}

\begin{abstract}
RESUMO: Diante das reformas da educação básica no Brasil, em particular no ensino médio, a análise comparativa com o sistema educacional de outros países pode servir como base para compreender os "baixos níveis de aprendizagem" no Brasil, mensurados pelo Programa Internacional de Avaliação de Alunos (PISA) de 2015. O texto propóe examinar, especificamente, a universalização e a obrigatoriedade da educação básica e as condições estruturais da educação considerada bemsucedida em países como Inglaterra e Finlândia. A análise foi realizada com base em fontes primárias e secundárias.
\end{abstract}

Palavras-chave: Ensino Médio. Educação comparada. Avaliação corporativa.

\section{HIGH SCHOOL AND INTERNATIONAL COMPARISONS: BRAZIL, ENGLAND, AND FinLAND}

ABSTRACT: Based on the reforms of the Brazilian primary education, particularly in high school, a comparative analysis with the educational system of other countries may be useful to understand the "lower levels of learning" in Brazil, which are measured through the 2015 Program for International Student Assessment. This study proposes to specifically examine the universalization and mandatory nature of the primary education and structural conditions of education considered to be successful in countries like England and Finland. The analysis was based on primary and secondary sources.

Keywords: High School. Compared education. Corporate evaluation.

\section{L'ENSEIGNEMENT SECONDAIRE ET LES COMPARAISONS INTERNACIONALES : LE BRÉSIL, L'ANGLETERRE ET LA FINLANDE}

RÉSUMÉ: A la suite des modifications à la formation de base au Brésil, en particulier dans le niveau secondaire, la comparaison entre le

\footnotetext{
*O artigo constitui desdobramento dos projetos de pesquisas: "Educação, Trabalho e Gênero. Políticas de formação profissional e de educação de adultos trabalhadores, na França e no Brasil: uma perspectiva comparada. Projeto de pós-doutorado, 2004 (Projeto FAPESP: 2003/12616-4); "Educaçáo de Adultos Trabalhadores: metodologias de ensino-aprendizagem, itinerários formativos e capacitação de professores" (Coordenadora) - 2002-2006 (Projeto Fapesp: 2000-13988-4

${ }^{1}$ Universidade de São Paulo, Faculdade de Educação - São Paulo (SP), Brasil. E-mail: moraescs@usp.br DOI: 10.1590/ES0101-73302017177657
} 
système éducatif brésilien et celui des autres pays peut s'avérer utile pour comprendre « le bas niveau d'apprentissage " au Brésil, mesuré par PISA (Programme International d'Evaluation d'Elèves) en 2015. L'article propose d'examiner, spécifiquement, l'universalisation et l'obligation de l'éducation de base ainsi que les conditions structurelles de l'éducation considérée effective dans des pays comme l'Angleterre et la Finlande. L'analyse a été exécutée sur la base de sources primaires et secondaires.

Mots-clés: Education secondaire. Education comparée. Evaluation corporative.

\title{
Introdução
}

\begin{abstract}
O modelo e os valores norte-americanos devem ser estendidos ao mundo; para definir este modelo, é necessário acrescentar ao fundamento das tradicionais liberdades a plena liberdade de empresa; portanto, o confronto náo deve ser apenas contra o comunismo, mas também contra a social-democracia (DOUTRINA TRUMAM, 1947 apud MAGRI, 2014).
\end{abstract}

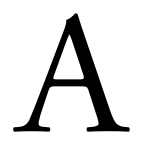

análise da organização da educação secundária para a juventude em dois países europeus, Inglaterra e Finlândia, pretende contrapor as trajetórias de países considerados emblemáticos na conformação de suas respectivas políticas educacionais baseadas em modelos distintos de configuração do Estado e de desenvolvimento socioeconômico. As aproximaçóes comparativas com o ensino médio do Brasil visam, principalmente, propiciar informaçóes para o desenvolvimento de algumas relaçóes consideradas relevantes à compreensão do atual impasse provocado pelas mudanças promovidas pela Lei de Reforma do Ensino Médio (Presidência da República, Casa Civil, Subchefia para Assuntos Jurídicos, Lei no 13.415 de 2017).

No que se refere às questóes metodológicas no campo da educação comparada, entende-se, de acordo com Epstein (2013, p. 541), que "a educação comparada é a aplicação das ferramentas intelectuais da história e das ciências sociais à compreensão dos problemas internacionais da educação", e que "os comparativistas diferem em suas definiçóes do campo porque essas definiçóes surgem da corrente epistemológica particular a que cada um adere" ${ }^{\text {. }}$

Nessa direção, a perspectiva teórica adotada pressupóe a apreensão da totalidade do social na sua historicidade (tempo-espaço), em seu movimento permanente na relação contraditória entre o global e as particularidades, as singularidades (COWEN, 2012; DALE, 2000; CIAVATTA-FRANCO, 2000). Como enfatiza Cowen (2012, p. 765-766), a relação tempo-espaço “ilumina as formas de expressão do 
poder social (econômico, político, cultural) no sistema educacional" e contribui para o enfrentamento das dificuldades analíticas do processo de transferência da educação de uma realidade social para outra (tríade nuclear de transferência, tradução e transformação), ao mesmo tempo em que possibilita superar pressupostos que definem como uma das tarefas principais do campo o "aconselhamento político aos governos".

A partir dessas orientaçōes, o exame dos países pretende revelar "que há algo que antecede os formatos atuais" dos diferentes sistemas escolares (VELOSO \& RODRIGUES, 2016, p. 7), ou seja, que a trajetória histórica específica às diferentes formaçóes sociais pode iluminar os cenários educacionais e atribuir sentido às suas particularidades.

O breve estudo comparado realiza-se a partir de fontes primárias e secundárias, indicadores sociais e educacionais, documentos e relatórios de organismos internacionais, estudos e pesquisas, bem como notícias publicadas na grande mídia.

\section{Algumas considerações iniciais}

Em nosso país, virou lugar-comum entre os "reformadores empresariais" (FREITAS, 2016) e seus aliados no âmbito governamental fazer apreciaçôes sobre a situação da educação pública brasileira, em particular do ensino médio, a partir de alguns indicadores educacionais, tomados, em geral, de forma isolada e descontextualizada, o que resulta em diagnósticos pejorativos e, até mesmo, catastróficos desta etapa da educação básica. Dados do Censo Escolar, tais como altos índices de evasão e reprovação existentes, associados a resultados de avaliaçóes internas (Índice de Desenvolvimento da Educação Básica - IDEB) e externas (Programa Internacional de Avaliação de Alunos - PISA, Organização para a Cooperaçáo e Desenvolvimento Econômico - OCDE) são utilizados para indicar "a realidade de um ensino médio falido, incapaz de cumprir metas e de atender às necessidades de seus estudantes" (CASTRO, 2016), quadro que justificaria a necessidade urgente de determinadas mudanças.

Entre as inúmeras manifestaçóes dos propositores/defensores da atual reforma do ensino médio brasileiro, divulgadas de forma espalhafatosa pela mídia e por sites de fundaçóes empresariais especializadas em consultoria educacional aos governos e promotoras de pesquisas nacionais sobre a educação pública ${ }^{2}$, selecionamos o discurso da atual diretora do ensino básico do Ministério da Educação (MEC), Maria Helena Guimarães Castro, o qual, a nosso ver, resume bem a visão e os objetivos educacionais que informam a nova lei reformuladora do ensino médio brasileiro (Lei no 13.415, de 2017):

Nosso modelo, que aplica um ensino igual para todos os alunos, é único no mundo. Como apelidou Cláudio Moura Castro, é o "ensino médio jabuticaba”, só tem aqui. Em países como França, Inglater- 
ra, Alemanha, Finlândia, Singapura e Austrália, o currículo do ensino médio se diversifica e se flexibiliza quando alunos atingem os 15 anos de idade. O próprio Pisa é aplicado a jovens de 15 anos, exatamente porque na maioria dos países o currículo é igual para todos até essa faixa etária. Nos Estados Unidos, a parte obrigatória do currículo, comum a todos, representa menos da metade da carga horária. A outra metade é composta por cursos eletivos, organizados pelos alunos de acordo com as suas preferências e interesses (CASTRO, 2016).

Cabe enfatizar, em primeiro lugar, que a organização do ensino médio brasileiro não é a "única no mundo". Ao contrário, a organização da educação secundária (denominação mais frequente e consagrada na região para a etapa localizada entre os ensinos primário e superior) de alguns países da Europa apresenta elementos comuns à brasileira, como se propóe indicar. É possível afirmar ainda que países cujos sistemas de ensino praticam menos a segregação precoce e favorecem a manutenção de um "tronco comum" por mais tempo na escolaridade básica obrigatória são os que alcançam melhores resultados educacionais, inclusive no PISA.

Autores como Baudelot e Establet (2009) sustentam a mesma avaliação em seus estudos. Segundo eles, apesar dos limites metodológicos e das implicaçóes políticas da avaliação internacional de larga escala, cujos resultados podem ser vistos como uma tentativa de homogeneização dos modelos educativos segundo os princípios da OCDE, a comparação entre os diferentes países tem contribuído para indicar que "a constituição de um tronco comum sólido é mais eficaz do que a realização prematura de fileiras (escolares) seletivas". É o caso da Finlândia, por exemplo, cujos estudantes têm obtido bons resultados em todas as avaliaçóes do PISA; ou da Polônia, que, na direção oposta de algumas recomendaçóes da OCDE valorizadas pelas autoridades brasileiras, em vez de flexibilizar/fragmentar o seu ensino secundário, "criou um ciclo secundário inferior unificado [...] que produziu claros efeitos", visíveis no melhor desempenho alcançado pelos estudantes nos testes, como observa Marie Duru Bellat (2015).

Por outro lado, segundo a autora, a Suécia, país em que os alunos alcançaram nas primeiras avaliaçôes "performances elevadas e igualitárias”, assistiu a degradação de seu desempenho após a implementação de uma "política de descentralização dos estabelecimentos e de liberalização, com um sistema de cheques escolares que permitiam aos alunos escolherem sua escola, o que promoveu uma segregação crescente dos estabelecimentos cujos alunos — os mais desfavorecidos - pagaram o preço" (BELLAT, 2015).

$\mathrm{Na}$ outra ponta, nos Estados Unidos e no Chile, países citados como referências para as mudanças educacionais no Brasil, a liberalização do mercado educacional e a flexibilização curricular no ensino médio geraram exclusão social, aprofundaram as desigualdades educacionais e levaram ao crescente rebaixamento do desempenho dos estudantes ${ }^{3}$. 
Baudelot e Establet (2009) enfatizam que "não há 'tronco comum' sem 'base comum' de conhecimentos". Uma escola que promove o acesso desigual ao conhecimento e reproduz e reforça as desigualdades sociais "obtém, ao mesmo tempo, resultados medíocres". Se a desigualdade é inerente às formações sociais capitalistas, são justamente as mais desiguais entre elas que obtêm resultados sofríveis no ranking da OCDE, como é o caso do Brasil ${ }^{4}$.

De acordo com os autores citados, "na França como nos outros países da OCDE, o desenvolvimento econômico e a elevação do nível escolar têm constituído, há um século, um círculo virtuoso" (BAUDELOT \& ESTABLET, 2009). Pelo inverso, "quanto menos uma sociedade é desigual, melhor é sua escola". Em resumo, a luta pela eficiência educacional e a luta pela igualdade social são uma única e mesma luta.

Considerando a diversidade histórica, social e cultural dos países da União Europeia, o que lhes confere significativas diferenças e disparidades, é possível observar em alguns deles conquistas importantes no campo educacional. A literatura costuma enfatizar de forma genérica, por exemplo, a ampliação da cobertura da educação secundária (correspondente ao ensino médio), em geral associada ao alargamento da escolaridade obrigatória e universal: no princípio do século $\mathrm{XX}$, apenas entre 5 e $10 \%$ dos europeus tinham acesso a alguma modalidade escolar, alcançando aproximadamente 15\% após a Segunda Guerra Mundial e, hoje, superando 90\%. Existiam, em 2005, seis vezes mais jovens escolarizados cursando o "ciclo médio" (SANTAMARIA, 2005, p. 17). Ao mesmo tempo, se há problemas específicos aos sistemas educativos de cada país, são encontradas também dificuldades similares entre eles, que tendem a se tornar cada vez mais comuns no contexto da globalização - como é o caso do crescente índice de abandono da educação secundária pelos jovens em situação de desemprego ou emprego precário, assim como a tendência cada vez maior à homogeneização das soluções para enfrentá-los, o que pode ser verificado na progressiva utilização das mesmas linguagens, nomenclaturas e políticas educacionais convergentes (DURIEZ et al., 1991).

Com essas preocupaçóes e levando em conta a globalidade e a complexidade da realidade educacional dos diferentes países, pretende-se problematizar os rumos das políticas públicas de educação na Inglaterra e na Finlândia. O escopo da análise está direcionado especificamente à configuração do ensino secundário nos sistemas educativos dos referidos países europeus, exemplos de situações antagônicas de organização educacional, de modo a relacioná-las ao ensino médio no Brasil.

\section{Políticas de Ensino Médio: Inglaterra}

O exemplo do Reino Unido é o mais propício para discutirmos as mudanças que, desde os anos 1970, vêm ocorrendo na quase totalidade dos países capitalistas, nos quais foram implantados, de modo sistemático e por diferentes 
governos (liberais, social-democratas e socialistas), programas de "modernização do Estado" traduzidos como "progresso democrático".

Os novos modos de gestão e as novas estruturas de poder nos sistemas educativos fazem parte do que se designa "Nova Gestão Pública", que se referencia basicamente na Gestão das Empresas. Na maioria dos casos, o processo consistiu em transpor para as organizações não empresariais os princípios de gestão e de qualidade experienciados nas empresas e, em seguida, impor a outros domínios da sociedade "um modelo gestionário e de exercício do poder segundo o qual o modo de governança se submete à cultura dos resultados" (BERGER \& TERRASECA, 2011, p. 8).

Segundo os autores (BERGER \& TERRASECA, 2011, p. 10), nesse modelo, que alguns designam de neoliberalismo, a decisão política, apresentada como simples evolução técnica, é estritamente guiada pelos dados fornecidos nos sistemas de informação administrativos e supóe a determinação de objetivos numéricos e indicadores de execução a partir dos quais se pretende avaliar a eficiência das políticas implementadas. A generalização da aplicação de regras de livre troca aos serviços e, em particular, aos serviços de educação fornecidos tanto pela União Europeia quanto pelo Banco Mundial, pelos acordos do General Agreement on Tariffs and Trade (GATT) e, posteriormente, da Organização Mundial do Comércio (OMC), consolida a tendência do que se convencionou chamar a "mercadorização" do saber e da educação, alcançando o conjunto das instituiçóes educativas.

Nos anos 1980, retomando universalmente o modelo liberal desenvolvido nos EUA a partir de Nixon e, sobretudo, de Reagan, "a mobilidade do capital colocou as instituiçóes educativas em competiçáo, quer no plano nacional quer no internacional" (BERGER \& TERRASECA, 2011, p. 10). Na Inglaterra, a "nova gestão pública" teve início com a administração liderada por Margaret Thatcher como primeira-ministra do Reino Unido, no período entre 1979 e 1990, sofrendo — na sua continuidade - permanentes adequaçóes nos governos que a sucederam, tanto pelos governos trabalhistas (New Labour), liderados por Blair, como pelo governo conservador de coalizão conservador/democrático liberal (2010-2015).

A privatização da educação emergiu fortemente como a principal característica das reformas educacionais promovidas pela "Nova Gestão Pública". O desmonte do "welfarismo" de pós-guerra de inspiraçáo keynesiana implantado nos anos 1950 e 1960 foi justificado por meio de um discurso que enfatizava as ineficácias dos governos e o custo excessivo de um Estado assistencialista, e foi associado a programas de reforma pública em desenvolvimento em outros países, como Holanda, Suécia, Austrália, Canadá e Nova Zelândia (HALL \& GUNTER, 2015, p. 747).

Em relação à educação, na Inglaterra, o discurso alimentado pelo Partido Conservador em inúmeros documentos — os Black Papers - afirmava a queda nos padrôes educacionais em escolas mantidas pelo Estado e defendia o controle dessas 
instituiçóes pelos pais, por meio de vouchers educacionais, e a competição entre as escolas (HALL \& GUNTER, 2015, p. 748). As preocupaçóes direcionavam-se, principalmente, aos métodos de ensino "progressistas", à escolarização abrangente ou comum iniciada nos anos 1950, aos níveis de autonomia dos professores, considerados excessivamente altos, e à ausência de mecanismos de responsabilizaçáo. Tal "invocação discursiva" assume forma definitiva e força política significativa quando passa a relacionar o declínio dos padróes educacionais a uma diminuição da competitividade econômica internacional do Reino Unido (HALL \& GUNTER, 2015).

A mudança histórica crucial consistiu em eliminar a concepção de educação, identificada com os princípios da "igualdade de oportunidades educacionais", ao projeto político que visava atender e estimular a demanda social pela igualdade de acesso à educação, de uma educação comum a todos, e substituí-la por uma visão de educação e sistema educativo que tem por "princípio político a concorrência econômica” (COWEN, 2005, p. 67). Nessa acepção, fundamentada nas teses marginalistas da Teoria do Capital Humano, as finalidades da educação derivam das necessidades econômicas e o indivíduo, enquanto sujeito de direitos, converte-se em consumidor dos serviços educacionais.

Em 1988, as prescriçóes do novo Ato de Reforma Educacional ofereciam a base para as posteriores mudanças que reestruturariam as instituiçóes educacionais inglesas: centralização do currículo, avaliação nas escolas por meios de testes nacionais de desempenho de alunos entre 6 e 16 anos e mercantilização via ampliação da diversidade escolar e escolha de escolas pelos pais.

A eleição de um governo do New Labour após 18 anos de administraçóes conduzidas por conservadores, embora promovesse alguns investimentos públicos na educação, deu continuidade à política neoliberal, desenvolvendo medidas que aprofundaram a privatização da educação, como a introdução de escolas independentes do Estado, com financiamento privado e fora do controle das autoridades locais. $\mathrm{O}$ processo de centralização das decisóes pelo governo central e o regime de responsabilização são mantidos, com a persistência da ênfase nas normas, no "controle de qualidade", na "gestão de competências" e nas escolas que fracassam (HALL \& GUNTER, 2015, p. 752). Além disso, o que nos interessa particularmente, desenvolve iniciativas para transformar todas as escolas de ensino médio em especializadas, "o que representou uma tentativa ampliada e mais determinada de desmembrar o sistema escolar abrangente, comum" existente desde os anos 1950 (COWEN, 2005, p. 71).

A formação dos professores passou a ser responsabilidade da nova Teacher Training Agency (TTA), "dominada mais pelo estado do que pelas instituiçóes acadêmicas", achando-se atualmente "estreitamente vinculada às escolas e à prática do ensino e distante das universidades", o que fez surgir sérias resistências no mundo acadêmico. A TTA enfatiza os nexos entre as normas de avaliação/classificação e a 
formação inicial dos professores, o que se definia em termos de competências para que pudessem ensinar de modo "efetivo" (COWEN, 2005, p. 76).

O ensino obrigatório tem início aos 5 anos, no ensino primário, e termina aos 16 anos, mas, segundo Cowen (2005), muitos alunos continuam na escola além dessa idade. Aproximadamente $90 \%$ dos alunos das escolas estatais de ensino secundário frequentam as chamadas comprehensive schools, que admitem alunos entre 11 e 18 anos. $\mathrm{O}$ ensino secundário é constituído por dois níveis: o inferior (entre 11 e 14 anos) e o superior (entre 14 e 16 anos). Os programas do ensino secundário superior são concebidos "para completar o ensino secundário no terciário ou fornecer competências relevantes para o emprego, ou ambos" (UNESCO \& CNE, 2015, p. 94).

Aos 16 anos, os alunos podem passar aos chamados sixthy-form colleges ou aos tertiary colleges. $\mathrm{O}$ certificado geral do ensino secundário, introduzido em 1988, é o principal exame pelo qual passam todos os alunos desse nível aos 16 anos ou mais. Os exames de nível A, que possibilitam a obtenção do General Certificate of Education (CGE), somente podem ser realizados após a obtenção do certificado de ensino secundário, ao término de dois anos ou mais de estudos, normalmente na Form VI das escolas secundárias, os colégios terciários ou os colégios de formação continuada (a chamada educação terciária pós-secundária), que preparam, respectivamente, para a progressão na educação (ensino superior) ou o emprego (COWEN, 2005; COMISSÃO EUROPEIA, 2015), conforme Gráfico 1.

O ensino privado atendia, em 2005 , apenas ao redor de $10 \%$ do grupo de idade correspondente aos níveis primário e secundário, mas o setor privado, como já se observou, tem sido fortalecido politicamente por meio de subsídios para que crianças mais pobres possam estudar em escolas privadas. Por outro lado, existem as chamadas public schools, que, apesar do nome, são privadas, elitizadas e de custo elevado, famosas por sua excelência, preparando os alunos para o acesso às universidades mais prestigiosas (COWEN, 2005, p. 75).

Como faz supor a arquitetura do sistema educacional na Inglaterra, tal organização visa propiciar escolhas precoces entre formação geral ou profissional no nível secundário superior, aos 14 anos. Essa formação pode ser complementada no pós-secundário. Além disso, a educação secundária e a formação profissional continuada tendem a constituir um conjunto mais integrado, com sobreposição dessa última sobre a forma escolar tradicional.

Nos anos 1970, com a crise econômica, o aumento do desemprego de jovens e o crescimento do número de alunos que permaneciam na escola, a política curricular na Inglaterra desenvolveu uma série de soluçôes pragmáticas. Organizaram-se novos currículos, nos quais "o conhecimento das disciplinas tradicionais foi enfraquecido para que atividades mais práticas, relacionadas com o trabalho e orientadas para a comunidade, pudessem ser incluídas", com o objetivo 


\section{Gráfico 1}

Estrutura dos sistemas educacionais - Inglaterra e Finlândia.
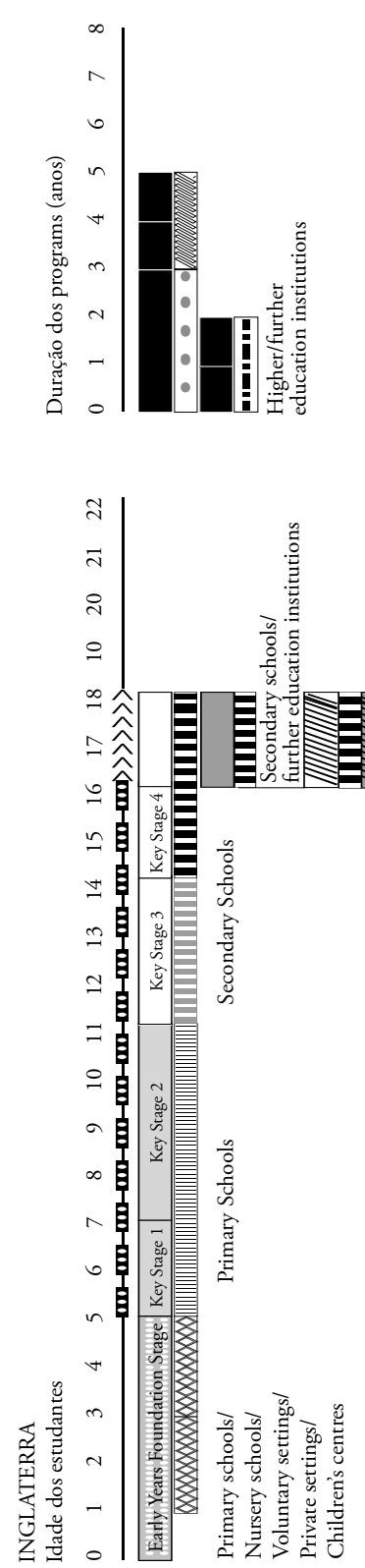
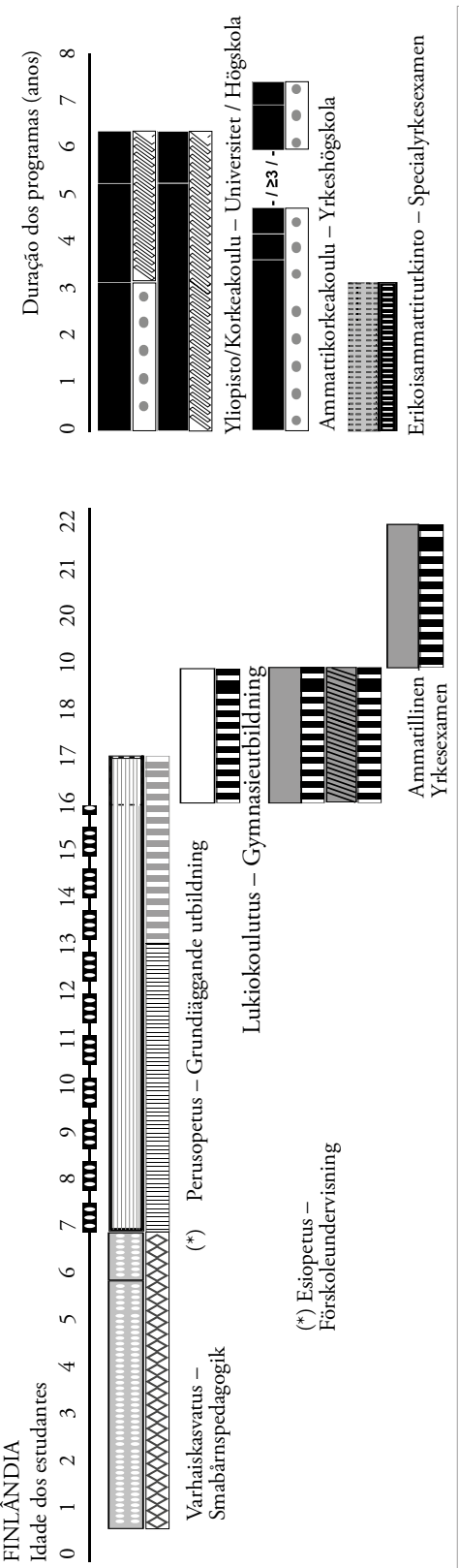

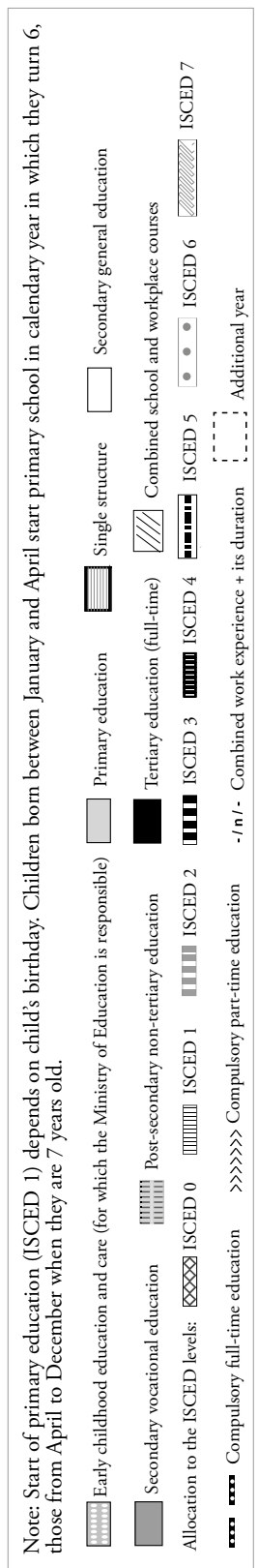

Fonte: grafico baseado em The Structure of the European Education Systems 2015/16: Schematic Diagrams. (European Union, 2015-16). 
declarado "de despertar o interesse da então denominada criança 'não acadêmica". No entanto, como observa Young (2006, p. 27), esses currículos, que "tratavam os critérios de conhecimento como se fossem flexíveis", acabaram por oferecer poucas chances de progressão nos estudos ou, até mesmo, na chamada empregabilidade.

É interessante demarcar, nessa direção, a proposta curricular definida pelo Ato Educacional de 1988, que permanece hoje e assemelha-se ao currículo do ensino médio prescrito na reforma brasileira do governo Temer. De acordo com Young (2016, p. 25), o Currículo Nacional definiu 10 disciplinas obrigatórias para todos os estudantes até os 16 anos. Progressivamente, no entanto, as exigências obrigatórias foram reduzidas até que, duas décadas depois, apenas as disciplinas de Matemática, Inglês, Ciências e Educação Religiosa permaneceram obrigatórias para todos os alunos até 16 anos. As escolas estavam livres para descartar História, Geografia, Línguas Estrangeiras e disciplinas isoladas de ciências (Física, Química e Biologia), sendo permitido o ensino de disciplinas "profissionalizantes".

A partir de 2007, houve mais duas etapas na modificaçáo da base de conhecimentos do currículo. A primeira consistiu na introdução de um modelo de avaliação por competências. Tais programas enfatizavam as competências e habilidades que os alunos adquiriam na comunidade local em detrimento do conhecimento das disciplinas. Ao mesmo tempo, um conjunto de níveis de equivalência foi estabelecido de forma que todos os programas pudessem ser classificados em uma mesma escala, independentemente dos seus diferentes modelos de avaliaçáo.

Os critérios e o foco das reformas mudaram em 30 anos, mas, na avaliação de Young (2016, p. 21), o relativismo implícito na distribuição de conhecimento permaneceu e as disciplinas escolares vinculadas à progressão para a universidade e até, em muitos casos, para a "empregabilidade" continuaram como direito de poucos, não de todos.

No que se refere especificamente à formaçáo continuada, o governo conservador (1979-1997) destruiu o sistema institucional de aprendizagem profissional, substituindo o regime de participação social tripartite (empresários, trabalhadores e Estado), em vigência entre os anos 1960 e 1980, por um regime neoliberal. O modelo britânico de formação e regulação dos mercados de trabalho tem por objetivo atender ao funcionamento do livre mercado, no qual os empregadores são dominantes em matéria de política pública. Tais estratégias contrastam com as dos modelos social-democráticos de outros países da União Europeia, como a França por exemplo, que se baseiam na regulação pelo Estado e pelos parceiros sociais. A formação profissional continuada foi considerada como responsabilidade do empregador e do indivíduo, e não do governo. Conforme Huddleston e Rainbird (2003, p. 118), os empregadores participam de diferentes maneiras da educaçáo e formação profissionais (Vocational Education \& Training - VET), e podem utilizar o setor do ensino público, por meio das Further Education Colleges, para formar seu pessoal e ofertar formações. 
A esse respeito, as autoras observam, a partir de suas pesquisas, que, no livre mercado da formação, ao contrário do que é considerado comumente, as "necessidades dos empregadores individuais" são heterogêneas, contraditórias e não expressam as demandas do conjunto da economia. Essas indicaçôes empíricas levaram-nas a interpretaçóes teóricas relevantes sobre a relação trabalho e educação que contrariam os rumos adotados na Inglaterra e que são válidas para o sistema educacional de diferentes países. Segundo elas, "a incerteza quanto à natureza futura do trabalho e da demanda de competências faz da formação geral 'longa' (a escola secundária de tronco comum), a que promove maior fundamentação para o desenvolvimento pessoal e o acesso a uma formaçáo posterior" (HUDDLESTON \& RAINBIRD, 2003, p. 123-134).

É também interessante considerar, nessa perspectiva, as ponderações de Cowen (2005, p. 85) sobre as dificuldades crescentes de a "retórica do mercado" - retórica da "escolha" e do "consumidor" — se manter diante do "fracasso relativo da educação entre alguns grupos, concretamente crianças de algumas minorias éticas" e do "aparecimento de grandes bolsóes de pobreza nas cidades":

A exclusão social e ausência de coesão social estão começando a aparecer como um dos preços que o sistema educativo inglês "concebido no mercado" tem que pagar por suas eficiências tão cuidadosamente gestionadas. Existe [...] a clara consciência de que o sistema educativo está 'em crise', mas a natureza da dita crise está começando a assumir uma ótica distinta. Ajustar-se à globalização econômica não constitui a finalidade única do sistema educativo que deveríamos alcançar. $\mathrm{O}$ que se observa na atualidade é uma preocupação algo tardia pela educação dos cidadãos (COWEN, 2005, p. 86).

\section{Políticas de Ensino Médio: Finlândia}

A Finlândia tem ocupado nas avaliaçóes do PISA, desde 2001, os primeiros lugares de "desempenho educacional e menor desigualdade entre escolas" e, ao mesmo tempo, aparece nos rankings internacionais como uma das economias "mais competitivas do mundo" e de "maior estabilidade econômica" (RANTANEN, 2014, p. 290).

A política educacional da Finlândia está ancorada em um tecido social bastante homogêneo e em uma visão historicamente construída sobre o papel do Estado no bem-estar social. A forma do Estado-providência ali desenvolvida com base "no universalismo e decommodification dos direitos sociais extensivos", "a igualdade dos padrōes mais elevados", e não das necessidades mínimas como em outros Estados-providência, tem sido classificada por alguns autores como regime "tipo 'social-democrata”" (ESPING-ANDERSEN, 1990 apud ANTIKAINEM, 2008, p. 33). 
Os processos que promoveram a qualidade educacional do país não são recentes. As informações levantadas indicam que as conquistas alcançadas foram construídas nas últimas quatro ou cinco décadas de priorização da educação pública, por meio de investimentos governamentais e reformas educacionais (BRITTO, 2013, p. 19; RANTANEN, 2004, p. 290).

Com a conquista da independência política em 1917, a nova Constituição (1919) estabeleceu a educação como dever do Estado e a gratuidade da educação primária. No início dos anos 1960, a educação gratuita e acessível a todos passou a ser um direito previsto na Constituição e, em 1968, uma nova reforma introduziu a escolarização básica de caráter público, universal e compulsório, de nove anos de duração, e "sem barreiras de seleção para o acesso ao ensino pós-primário". Nesse processo, por "amplo consenso político", o parlamento finlandês com participação ativa da sociedade civil definiu "um projeto de unificação do ensino fundamental", e a implementação das comprehensive schools em todo o país concretizou-se no final dos anos 1970 (BRITTO, 2013, p. 9; ANTIKAINEM, 2008, p. 34).

De acordo com as leis da Finlândia, compete às autoridades públicas garantir educação gratuita em todos os níveis educacionais, desde o pré-primário ao ensino superior, e o direito à educação permanente para toda a sociedade. Apenas uma parcela dos cursos voltados para a educação adulta está excluída do regime de gratuidade (RANTANEN, 2004, p. 293).

O "Plano de Desenvolvimento para a Educação" abrange todos os níveis educacionais e, entre os seus objetivos, estão "a redução da pobreza, da desigualdade e da exclusão, com vistas a estabilizar a economia política e fomentar o crescimento econômico sustentável de empregos e competitividade" (PDE 2011-2016 apud RANTANEN, 2004, p. 294). Peça-chave na unificação do ensino fundamental no país foi a construção de um novo currículo básico, como "um guia de referência nacional".

A educação pré-escolar não é obrigatória na Finlândia, embora os municípios sejam obrigados a ofertá-la, gratuitamente, como opção a todos. A educação básica primária finlandesa inclui 9 anos ou séries obrigatórias (dos 7 aos 16 anos), e uma $10^{\text {a }}$ série opcional direcionada aos alunos com baixo rendimento e à "preparação de imigrantes", com vistas a suprir o aprendizado para prosseguimento dos estudos no ensino secundário. Até a sétima série, as classes são de responsabilidade de um único professor que ministra todas as disciplinas do currículo; nas séries posteriores, cada disciplina possui um professor especializado. As escolas, de tempo integral, oferecem ao aluno refeição quente diária e assistência médica, dentária e psicológica. O governo arca com os custos de transporte e os estudantes, quando necessário, têm direito à hospedagem em dormitório pago pela escola. Em 2009, $45 \%$ das escolas finlandesas acomodavam menos de 100 alunos (RANTANEN, 2004, p. 295). 
O ensino privado é bastante restrito no país. Em 2005, apenas $1 \%$ dos estudantes de ensino fundamental, 4\% do secundário inferior e $10 \%$ do secundário superior frequentavam escolas privadas (OCDE, 2005 apud ANTIKAINEM, 2008, p. 35). Grande parte delas desenvolve educação básica para adultos e imigrantes, e a maioria tem caráter confessional ou de comunidades linguísticas, além daquelas dirigidas a alunos com necessidades especiais. As escolas privadas, contudo, são também financiadas com recursos públicos e oferecem ensino gratuito.

O ensino secundário, como prosseguimento dos estudos do ensino básico aos alunos na faixa etária entre 16 e 19 anos, está organizado em 3 anos, mas pode ser realizado em 2, 3 ou 4 anos. De acordo com o decreto geral das Escolas Secundárias de 1998, o objetivo desta etapa escolar é proporcionar aos alunos "os conhecimentos e as habilidades necessárias não apenas para os estudos posteriores, mas para a vida, seus interesses pessoais e o desenvolvimento de sua personalidade no mercado de trabalho" (RANTANEN, 2014, p. 301). Ao concluírem a escola básica (primária), os estudantes podem optar por ingressar no ensino secundário tradicional ou no técnico-vocacional. Há, no entanto, alunos que cursam o secundário tradicional e, posteriormente, decidem igualmente cursar o técnico.

Conforme as informaçóes levantadas pelos referidos autores (ANTIKAINEN, 2008; RANTANEN, 2014; BRITTO, 2013), o ensino secundário tradicional não possui divisão por séries e as disciplinas não estão vinculadas a anos específicos. Os estudos são divididos em disciplinas obrigatórias, cursos de especialização complementares e de livre escolha dos alunos, bem como matérias aplicadas. $\mathrm{Na}$ Finlândia, diferentemente da Inglaterra, o currículo visa ampliar a educação básica comum e é constituído pelo ensino de: Língua Materna e Literatura (finlandês ou sueco, línguas oficiais do país), Línguas Estrangeiras, Matemática, Ciências Naturais, Ciências Humanas e Sociais, Religião ou Ética, Educação Física, Biologia, além de Artes e Disciplinas Aplicadas. Consideradas "de integração", essas matérias incluem elementos de várias áreas de conhecimento, cursos metodológicos ou específicos priorizados pela escola, e podem englobar certificação técnica em Artes, Música e Educação Física, por exemplo. No final do ensino secundário, os estudantes fazem "exame de matrícula", que é um pré-requisito para a entrada no ensino superior.

O ensino técnico-vocacional é voltado para os alunos entre 16 e 25 anos. Corresponde à educação profissional técnica integrada ao nível médio no Brasil, e seu objetivo é propiciar aos alunos "conhecimentos e habilidades necessárias para desenvolver a competência profissional, proporcionando-lhes a possibilidade de ingressar no mercado de trabalho" e "prepará-los para a continuidade de estudos ao longo da vida" (RANTANEN, 2014, p. 304). A duração do ensino profissional é de três anos, os estudos são feitos em tempo integral e as matérias obrigatórias planejadas, geralmente, a cada ano. O programa de ensino desenvolve as seguin- 
tes "áreas de estudo": Ciências Humanas e Educação; Cultura; Ciências Sociais, Negócios e Administração; Ciências Naturais; Tecnologia, Comunicação e Transporte; Recursos Naturais e Meio Ambiente; Serviços Sociais, de Saúde e Esportes; Turismo, Hotelaria e Serviços Domésticos, e todas as áreas incluem, no mínimo, seis meses de estágio.

Um dos resultados eloquentes da reforma do ensino fundamental foi o aumento de demandas pelo ensino médio: em 1970, apenas 30\% dos finlandeses cursavam essa etapa e, em 2013, essa proporção chegou a $90 \%$. Vale ressaltar que a frequência ao ensino médio nunca foi obrigatória no país. Recentemente, este passou por nova reforma, com o fortalecimento da educação integrada e, hoje, mais de $40 \%$ dos alunos optam pela modalidade integrada à educação profissional (OCDE, 2017, p. 57). É importante destacar que os diplomas das diferentes modalidades de ensino médio dão acesso a ambos os tipos de ensino superior: as universidades e as politécnicas (BRITTO, 2013, p. 10).

Ao contrário do que acontece no Reino Unido, a escola técnica profissional de nível médio é socialmente valorizada pela alta qualidade de sua formação, viabilizada por significativos investimentos públicos. De acordo com dados fornecidos pela OCDE (2017, p. 104), países em que "os efetivos da formação em alternância são numerosos no segundo ciclo do secundário", como é o caso da Finlândia (ao lado da Alemanha e dos Países Baixos), os recursos públicos, por aluno, na educação profissional são 20 a 30\% superiores aos destinados à formação geral.

Outro aspecto crucial na construção do modelo de ensino fundamental universal foi o reconhecimento de que, para a existência de um sistema educacional democrático capaz de atender igualmente a todos os alunos, independentemente de "aptidóes específicas, status socioeconômico ou origem familiar", seria "imprescindível [...] um corpo docente altamente qualificado". Esse reconhecimento levou à alteração da formação inicial dos professores de educação básica, que é realizada atualmente nas universidades com a exigência, além da licenciatura na área de conhecimento específica, da obtenção do título de mestre. Em geral, os professores — bem pagos — são selecionados entre os $10 \%$ melhores colocados em seus respectivos cursos nas universidades, o que indica grande procura pela profissão. A docência é em tempo integral e, geralmente, desenvolvida em um único estabelecimento. Os professores detêm autonomia em sala de aula, na escolha do método de ensino e dos livros didáticos, bem como têm poder de decisão sobre a política e gestão escolar, participando da elaboração do currículo escolar (BRITTO, 2013; RANTANEM, 2004).

É importante indicar, por outro lado, que, apesar dos avanços considerados, a Finlândia não tem ficado imune à influência transnacional. A globalização acelerada e o aumento da competição econômica e da mudança tecnológica têm levado à introdução de políticas neoliberais no país, "embora sob a retórica de manter e salvar o welfare state” (NYYSSÖNEN, 2008, p. 37). Segundo Antikai- 
nen (2008, p. 37), mudanças podem ser observadas na economia nacional e na política social. Elementos do Estado competitivo "estão sendo montados a partir do global ou, pelo menos, de fontes transnacionais, como a OCDE e a UE". No campo educacional, por exemplo, no início dos anos 1990, a educação vocacional de adultos foi objeto de reforma, de modo a ser dirigida para o mercado, e qualificaçôes baseadas em competências foram adotadas, para, em seguida, serem introduzidas na educação vocacional de jovens, com a crescente presença das associações de empregadores na política educativa vocacional (ANTIKAINEN, 2008).

Embora documentos do Governo, em particular aqueles relativos às políticas de inovação tecnológica, apoiem o sistema de escola compreensiva, setores da elite econômica e funcionários do governo defendem "medidas promotoras da competiçáo, do managerialismo e da performatividade na educaçáo" (ANTIKAINEN, 2008, p. 42). Por outro lado, a aplicação de novas estratégias políticas depende "de sua legitimação a longo prazo e socialização concordante", e pesquisas de opinião pública indicam que mais de $80 \%$ da população têm posição contrária e apoiam o Estado-providência (ANTIKAINEN, 2008, p. 46).

\section{Brasil, Inglaterra e Finlândia: semelhanças e diferenças - à guisa de conclusão}

Por meio do breve exame da realidade educacional de dois países considerados representantes da diversidade existente na Europa, ou seja, Inglaterra e Finlândia, foi possível constatar a inexistência do "ensino médio jabuticaba" brasileiro, isto é, que o sistema unificado e global de conhecimento como base da educação básica, agora interpelado, não pode ser visto como único nem considerado extemporâneo.

Uma ambiguidade inicial e recorrente pode ser observada no discurso justificador da atual reforma do ensino médio: apesar de pretensamente homogeneizar a organização dos sistemas educativos, deslocando-os da história e da cultura dos respectivos países, de sua realidade econômica, política e social, e, em consequência, ignorando as formas de relacionamento das forças sociais que lhes são constitutivas, realiza escolhas entre esses sistemas e elege um deles como o modelo funcional e adequado para o Brasil (MORAES, 1995). Da mesma maneira, as razões dessas escolhas são, em geral, apresentadas de forma simplista e reducionista, além de serem delimitadas a aspectos funcionais da educaçáo escolar, tais como a alegada inadequação do currículo aos interesses e às expectativas juvenis.

A fala dos reformadores empresariais explicita sua preferência pelo modelo anglo-saxão de organização educacional, que tem no Reino Unido (e nos Estados Unidos) o seu paradigma. $\mathrm{Na}$ Inglaterra, como foi exposto, as estruturas do Estado social foram destruídas e as reformas educacionais implantadas pela 
Nova Gestão Política (NGP), neoliberal, a partir dos anos 1980, desmantelaram o sistema educacional público, substituindo-o por um sistema educacional privado, "no qual as escolas competem ferozmente em um mercado educacional onde os propósitos da educação são redutoramente simplificados a pontuações e testes" (HALL \& GUNTER, 2015, p. 755).

Nesse tipo de reforma, como se procurou evidenciar, estratégias sobre controle, avaliação e performatividade dos sistemas de educaçáo e formação, que emanam de organizaçóes internacionais como o Banco Mundial, o Fundo Monetário Internacional e a OCDE, visam dar legitimidade ao sistema educacional "moderno", conferindo-lhe características básicas necessárias à sua adequação ao ambiente econômico globalizado, competitivo e mutável. Além da terminologia proveniente de abordagens econômicas marginalistas da Teoria do Capital Humano, como competitividade, produtividade, adaptabilidade, empregabilidade, entre outras, são introduzidos processos de monitoramento, responsabilização, controle total de qualidade, indicadores e marcos referenciais para descrever os instrumentos básicos a serem utilizados nas economias baseadas no conhecimento (OCDE, 2002).

Além disso, o que é fundamental a esse tipo de concepção que prioriza resultados, competências, produtos de aprendizagem e quantificaçóes, modifica significativamente a natureza do conhecimento buscado pelo sistema educacional. Conhecimento aceitável é conhecimento útil, mensurável. De acordo com Pasias e Roussakis (2012, p. 600), "no contexto de uma economia tecnocrática baseada no conhecimento, o conhecimento é um produto-commodity comercial que pode se tornar 'consumível' e que é renovável”. Não só o conhecimento é visto como consumível, "mas também o objeto do conhecimento e o sujeito do conhecimento, tanto individual como coletivo". Foi o que observamos na substituição do currículo nacional britânico, que era fundamentado em disciplinas acadêmicas, por outro baseando em competências, nos anos 2000, ou nas suas políticas de livre mercado na formação continuada ou aprendizagem ao longo da vida, por exemplo.

No Brasil, a escolha desse modelo educacional pelo grupo que hoje detém hegemonia no Ministério da Educação vem dar continuidade e aprofundar as medidas iniciadas, na década de 1990, de implantação da NGP, referenciada, por sua vez, na reforma realizada na Grã-Bretanha (OLIVEIRA, 2015). A transposição do Managerialism como modelo de organização de administração pública foi defendida por Bresser Pereira (1999, p. 32), Ministro da Reforma de Estado à época, que o definiu como "um conjunto de ideias e crenças que toma como valores máximos a própria gerência, objetivo de aumento constante da produtividade, e a orientação ao consumidor".

Não cabe ao escopo do trabalho analisar o processo de desenvolvimento da NGP no Brasil. Vale assinalar que o contexto de introdução e disseminação de seus princípios e práticas — desde o final da Ditadura Civil Militar até o gover- 
no Dilma Rousseff (1964-2016) — foi marcado por movimentos contraditórios, sendo que sua implementação recebeu primazia na agenda governamental de Fernando Henrique Cardoso (1995-2012), de clara orientação neoliberal, e experimentou alguns recuos em meio a intensas disputas no governo Lula.

A aprovação da nova Constituição Brasileira, em 1988, e da Lei das Diretrizes e Bases da Educação Nacional - LDB (Lei no 9394/96) expressa com clareza as tensóes entre a ofensiva neoliberal e as pressóes dos movimentos sociais organizados pela ampliação dos direitos e pela maior democratização da educação. Em relação aos direitos de cidadania, a nova Constituiçâo estabelece uma regra política democrática e amplia a cobertura da proteção social a todos, independente do vínculo formal de trabalho, reconhecendo a existência dos direitos coletivos; ao mesmo tempo, permanecendo a velha articulaçáo entre o Estado e o mercado, no momento que o processo de transnacionalização e a ideologia neoliberal ganham dimensão mundial (SALLUM JR., 2003; MORAES, 2006). O texto da LDB também traduz a disputa entre reivindicaçóes por uma efetiva democratização do acesso ao conhecimento em todos os níveis (FRIGOTTO \& CIAVATTA, 2003, p. 97) e o ajuste dos sistemas educacionais às demandas da nova ordem econômica.

Nas reformas neoliberais implementadas pelo governo Fernando Henrique Cardoso, houve prevalência da contenção dos gastos públicos e do direcionamento focalizado das políticas sociais a seguimentos específicos, em detrimento da cobertura universal de alguns direitos. Por sua vez, as medidas desenvolvidas nos oito anos de governo Lula (2003-2010) evidenciam contradição entre propostas que se orientam na continuidade das políticas neoliberais herdadas, de flexibilização e mercantilização dos direitos sociais, e aquelas que propóem a implementação de um projeto voltado para a construçáo de um modelo alternativo de desenvolvimento econômico e social-democrático. O embate é perceptível nas dificuldades de implementação de políticas universais, permanentes, substituídas por uma multiplicidade de políticas públicas de caráter provisório e assistencialistas, fragmentadas em vários ministérios no âmbito central do governo.

As políticas educacionais apresentaram, assim, caráter "pendular e ambíguo" (OLIVEIRA, 2015, p. 636): ao mesmo tempo que foi ampliada a destinaçáo de recursos públicos a gastos sociais, com o desenvolvimento de programas de inclusão social (Bolsa Família, Mais Educação) para o acolhimento de setores historicamente excluídos da população, reforçou-se e ampliou-se o sistema de avaliação da educação básica e do ensino superior iniciado no governo anterior.

No campo da educação básica, a Emenda Constitucional no 5, de 2009, amplia a obrigatoriedade escolar por faixa etária dos 4 aos 17 anos, induzindo uma expansão de duas etapas da educação básica: a educação infantil e o ensino médio. Portanto, alterou-se a medida do governo anterior, que aprofundara a dualidade de ensino, e reintegrou-se a educação profissional técnica ao ensino médio (Decreto ${ }^{\circ}$ 5.154/04, o qual substitui o Decreto no 2.208/97), complementada posteriormente 
por aprovação tardia, pelo Conselho Nacional de Educação, das Diretrizes Curriculares Nacionais do Ensino Médio (Parecer CNE/CEB 05/2011), que são fruto de intensa mobilização de educadores e suas associações representativas (sindicais e científicas). Além disso, organizou-se o Programa de Integração da Educação Profissional ao Ensino Médio na Modalidade de Educação de Jovens e Adultos (Proeja), posteriormente ampliado com o Programa de Integração da Educação Profissional à Educação Básica na Modalidade Educação de Jovens e Adultos - Proeja-FIC (Decretos no 5.478/2005 e no 5.840/2006), destinado ao atendimento de (milhóes) trabalhadores que não concluíram a educação básica na idade adequada.

O conjunto dessas medidas caminha no sentido do resgate e da revitalização da educação de jovens e adultos de modo a superar o viés assistencialista e compensatório, promovendo a inclusão social (MORAES, 2006, p. 406-407). Tais políticas públicas, associadas àquelas de expansão da Rede Federal de Educação Tecnológica (Lei no 11.892/2008), apesar de não se constituírem em políticas de Estado, têm o mérito de propor integrar a formação escolar e a formação para o trabalho e para a cidadania, incorporando o tema do trabalho como o eixo estruturante da proposta curricular (IIEP \& GP TRABALHO E EDUCAÇÁO DA FEUSP, 2011, p. 8).

Em meio aos embates, os programas tiveram difícil operacionalização e, na gestão Dilma Rousseff, decretou-se sua extinção a partir da criação do Programa Nacional de Acesso ao Ensino Técnico e ao Emprego (PRONATEC, Lei ${ }^{\circ}$ 11.513/2011), política privatizante que contou, na sua elaboração, com destacada participação de entidades representativas dos empresários.

Em síntese, os governos Lula e Dilma (2011-2016) cuidaram da expansão dos ensinos médio, técnico e superior, visando ampliar o acesso a maiores segmentos populacionais, em particular os mais pobres, embora com grandes concessóes aos proprietários das instituiçóes privadas e ao ideário empresarial da educação funcional ao mercado 5 .

O grupo político do governo atual esmerou-se em aprovar um instrumento de lei, na forma de Medida Provisória (MP) no 746/2016, ao qual se soma o Projeto de Lei no867/201 ("Escola Sem Partido"), que se institui "como a contrarreforma na educação do Golpe de Estado de 31 de agosto de 2016" e "legaliza o apartheid social na educação no Brasil" (FRIGOTTO, 2016).

Tal como ocorre na Inglaterra, propóe-se estabelecer um currículo mínimo no ensino médio, baseado no modelo das competências, cujas disciplinas, como definido pela OCDE, respondem aos interesses declarados do mercado globalizado e flexível, impedindo o exercício do direito ao conhecimento propiciado pela educação de base, comum a todos, universalizada. Ao mesmo tempo, destrói-se o ensino técnico profissional público de qualidade, substituindo-o por uma formação profissional fragmentada em módulos e formatada para permitir sua terceirização 
a organizações não governamentais (ONGs), empresas educacionais e associações empresariais, e a ampliação do mercado educacional. Assim como na Inglaterra, observa-se a aproximação entre instâncias educativas e campo econômico, "com predomínio de uma lógica adequacionista que funciona como orientação normativa ou referencial de ação pública” (MAROY \& DORAY, 2003, p. 292).

Concordamos com as análises que qualificam o ensino médio no Brasil não pelo denominado "fracasso", mas pela ausência de políticas públicas que promovam sua oferta universalizada e de qualidade como direito a ser garantido a todos os brasileiros ${ }^{6}$. Padróes de qualidade educacional elevados e bom desempenho dos estudantes serão alcançados apenas por meio de políticas e recursos públicos que viabilizem escolas bem equipadas, professores valorizados e com carreira e condiçóes de trabalho, corpo técnico estável e projeto pedagógico integrado de formação humana de base.

O exemplo apresentado da educação da Finlândia contribui para nossa reflexão. Se a experiência educacional finlandesa tem raízes históricas, políticas, culturais e sociais próprias que não podem ser transpostas para outros contextos, por outro lado, ao entender o que está por trás de exemplos bem-sucedidos, podemos refletir sobre a nossa própria trajetória de políticas educacionais e os caminhos prospectivos que se delineiam (BRITTO, 2013, p. 18).

Trata-se, em primeiro lugar, de considerar os fatores socioeconômicos e o grau de desenvolvimento dos países. Portanto, deve-se analisar os sentidos da ação do Estado e de sua regulação institucional em diferentes contextos sociais. Nessa direção, os próprios relatórios internacionais do PISA, a cargo da OCDE, apesar de seus vieses e pressupostos de avaliação, indicam importantes diferenças no desempenho dos alunos segundo o nível de renda agregada, os investimentos públicos em educação, a organização do sistema educacional e as condições de vida de cada país participante (BRITTO, 2013, p. 19). Ao mesmo tempo, a análise complementar deve apreender como as políticas estruturais, “externas à escola”, informam as políticas educacionais e se expressam nos aspectos "intraescolares", os quais podem incidir na distribuição das oportunidades educacionais e na qualidade da educação.

Em primeiro lugar, a Finlândia tem resistido às investidas neoliberais, mantém a sua configuração de Estado social que intervém na regulação social e atua na manutenção e na ampliação da equidade social por meio de investimentos substantivos nas políticas sociais e na centralidade dada às chamadas políticas de pesquisa, desenvolvimento e inovação (P\&D\&I) desde o final dos anos 1980 — 1,7\% do produto interno bruto (PIB) em 1980 para 3,4\% em 2000 - mais do que o dobro do que aplicam o Reino Unido (1,76\% em 2008) e o Brasil (1,16\% em 2008) (BRITTO, 2013, p. 18; OCDE, 2015, p. 53).

Em segundo lugar, além de ser um país de distribuição de renda mais homogênea que a maioria dos estados europeus, a Finlândia aplica um percentual 
significativo do seu PIB em educação, 6,8\% em 2012, e o financiamento da educação, como foi visto, é quase totalmente público, com apenas $0,2 \%$ de gastos privados (HELENE, 2012). Não há limitações de recursos materiais e institucionais, o que coíbe a reprodução de desigualdades sociais na escola ${ }^{7}$.

Em terceiro lugar, a Finlândia adotou estratégias divergentes das recomendaçóes hegemônicas da agenda da reforma educacional disseminada a partir de 1990, especialmente no que se refere ao papel da avaliação e da padronização do ensino. Não implementou o pensamento ortodoxo sobre política educacional inspirada nos modelos empresariais da educação, como a Inglaterra e o Brasil: não introduziu prescriçóes curriculares rígidas e padronizadas enfocando habilidades básicas em leitura e matemática; não intensificou o uso de testes padronizados externos para avaliação da aprendizagem dos alunos; não estimulou a competição entre escolas e não utilizou mecanismos de responsabilização direta dos profissionais da educação pelos resultados alcançados, seja por meio de incentivos positivos como bônus ou remuneração por mérito e premiaçóes, seja por sançôes. Rejeitou, portanto, a cultura dos testes e dos vouchers que permitem mercantilizar o acesso às escolas. No entanto, isso não significa que a Finlândia não utilize formas de avaliação no processo educativo. Provas são usadas apenas para informar aos professores sobre o desenvolvimento do trabalho, mas jamais para classificar, punir ou recompensar alunos, escolas ou professores. Certamente, tais procedimentos só podem ter êxito em um contexto em que a qualidade da formação docente e o prestígio social dos professores estão consolidados. Os professores da Finlândia, além de terem boas condições de trabalho, são bem remunerados (BRITTO, 2013, p. 20; HELENE, 2012).

Por fim, a Finlândia reforçou a formação acadêmica e fortaleceu a educação profissional integrada ao ensino médio, fazendo valer o direito da população ao conhecimento, a uma educação comum e de igual qualidade para todos.

A experiência educacional finlandesa poderia ensejar oportunidades interessantes para o Brasil. No entanto, apesar das evidências, o paradigma adotado é o de políticas e práticas educacionais e sociais que já se mostraram perniciosas em muitos países. A política do atual governo não é sensível às comparaçóes internacionais indicativas de que países nórdicos como a Finlândia, bem como outros países, "com setor público extenso e elevada taxa de impostos, podem ser altamente competitivos" (ANTIKAINEN, 2008, p. 42). Sua opção é a de se sujeitar às agendas educacionais, econômicas e políticas dominantes da globalização, um projeto de integração econômica que reforça a segregação e a marginalização social. Atualmente, os ajustes da economia e as medidas de austeridade impostas pelas classes dominantes à população brasileira e especificamente à classe trabalhadora, da cidade e do campo reforma da previdência e trabalhista e congelamento por 20 anos da ampliação de investimentos na educação e na saúde públicas - são paradoxalmente mais severos que aqueles emanados das recomendaçóes da OCDE. Essas, por 
exemplo, elogiam programas governamentais como o Bolsa Família e sugerem maiores investimentos de recursos públicos no Sistema Único de Saúde (SUS), visto como referencial para outros países no combate à pobreza e para a inclusão social (OCDE, 2015, p. 31-32). Isso nos leva a indagar a respeito de qual projeto de país está em curso no governo Temer.

É evidente que a resposta a esses e outros questionamentos, como se procurou evidenciar no trabalho, só pode ser apreendida em uma análise que situa a educação no âmbito das forças sociais em presença. As diferenças e semelhanças observadas nos países estudados não resultam senão de suas respectivas trajetórias históricas, de elementos constituintes da relação capital-trabalho e da ação de atores políticos diversos para compor suas políticas de educação. A compreensão da dialética das mudanças sociais e educacionais, mudanças nas relações entre educação e trabalho, pressupóe um estudo paralelo sobre os processos de reprodução das classes sociais. Isso implica considerar as decisóes políticas em termos de igualitarismo e de seleção/exclusão no campo da educação e nos processos de desenvolvimento econômico e social. Foi o que se propôs realizar no exame comparado do ensino médio.

\section{Notas}

1. Sobre as tendências e os desenvolvimentos no campo da educaçấo internacional e comparada (EIC), consultar Amaral (2015); Gorostiaga (2013) e Nóvoa (1998).

2. São instituiçōes financeiras e empresas: Itaú/Unibanco, Bradesco, Santander, Gerdau, Natura, Volkswagen, além das fundaçôes Victor Civita, Roberto Marinho e Lemann, bem como organizaçóes como o Centro de Estudos e Pesquisas em Educação, Cultura e Ação Comunitária (CENPEC), Todos pela Educação, Amigos da Escola, todas diretamente envolvidas na "expulsão das antigas formas de gestão da educaçáo como bem público” (BARRETO, 2016, p. 777).

3. Sobre a educação no Chile, consultar Adrião \& Gil (2009). Para uma visão crítica da educação nos EUA, ver Moraes (2014); Berliner \& Biddle (1995).

4. Estudos da OCDE (2016) indicam que a renda média anual dos países participantes, em 2013, variou entre 4.000 USD (México) e 38.500 USD (Luxemburgo), oito vezes maior que a mais baixa. Finlândia e Alemanha têm rendas médias equivalentes a 25.000 USD, acima da média da OCDE (20.000 USD), seguidos pela França (23.000 USD) e Reino Unido (20.000 USD). A renda média per capita no Brasil, em 2015, era de 11.199 USD (UNESCO \& CNE, 2015). De acordo com o Coeficiente de Gini calculado em 2012, que mede a desigualdade na distribuição de renda em uma escala de 0 a 1 e cujos valores mais elevados correspondem às mais fortes desigualdades de renda, os países portadores de menor desigualdade são a Finlândia $(0,2)$, ao lado dos Países Escandinavos, da França e da Alemanha (0,3). O Brasil (entre 0,5 e $0,6)$ é o terceiro país mais desigual, superado ligeiramente pela Colômbia e pelo Zaire (entre $0,6$ e 0,7$)(\mathrm{OCDE}, 2015$, p. 31). 
5. As matrículas no ensino médio aumentaram, no Brasil, de 3,7 milhóes em 1991 para 8,3 milhôes em 2010. Mas, em 2014, dos 10,5 milhóes de pessoas entre 15 e 17 anos, somente 5 milhões estavam matriculadas no ensino médio, o que corresponde a 59,5\% dos brasileiros nessa faixa etária. Cerca de 3,5 milhóes ainda cursam o ensino fundamental e mais de 1,5 milhão estão totalmente fora da escola (MEC/INEP, 2015). Nesse mesmo ano, apenas 29,5\% dos jovens entre 14 e 29 anos possuíam ensino médio completo (DIEESE, 2015). A desigualdade de acesso à educaçáo e aquela produzida e/ou reforçada no interior da escola continuam como um problema a ser enfrentado pela política pública de educação.

6. A esse respeito, ver Simões (2016) e Girotto (2017).

7. No Brasil, o investimento público direto em educação atingiu 5\% do PIB em 2014, 6\% se incluirmos o investimento total que incorpora os recursos públicos repassados à inciativa privada. Analisando o total de recursos investidos no ensino médio (R \$ 64.510.000,00 em 2014), dividido pelo número de matrículas nessa etapa da educação básica (6.427.370), temos o valor de $\mathrm{R} \$ 10.036$ por aluno/ano (R\$ 836 por aluno/mês), cerca de um terço da média dos países da OCDE (EDUCATION AT A GLANCE, 2016 apud GIROTTO, 2017, p. 3).

\section{Referências}

ADRIÃO, T.; GIL, J. (Orgs.). Educação no Chile: olhares do Brasil. São Paulo: Xamã, 2009. AMARAL, M.P. Tendências, desafios e potenciais da educação internacional e comparada na atualidade. Revista Brasileira Estudos Pedagógicos, Brasília, v. 96, n. 243, p. 259-281, maio/ago. 2015.

ANTIKAINEN, A. A reestruturação do Modelo Nórdico de Educação. Revista Lusófona de Educação, v. 11, p. 31-48, 2008.

BARRETO, Raquel G. Entre a Base Nacional Comum Curricular e a Avaliação: a substituição tecnológica no ensino fundamental. Educação e Sociedade, Campinas, v.37, n. 136, p. 775-791, jul.-set.,2016

BAUDELOT, C.; ESTABLET, R. Interview Jean-Michel Zakhartchouk sur L'élitisme républicain - L'école française à l'épreuve des comparaisons internationalles. Paris, Seuil, 2009. 120 p. Disponível em: <http://www.cahiers-pedagogiques.com/L-elitisme-republicain-Lecole-francaise-a-l-epreuve-des-comparaisons-internationales $>$. Acesso em: 26 fev. 2017.

BELLAT, M.D. Inégalités scolaires: quelles pistes politiques? 2015. Disponível em: $\leq$ https:// theconversation.com/inegalites-scolaires-quelles-pistes-politiques-48109>. Acesso em: 10 mar. 2017.

BERGER, G.; TERRASECA, M. Políticas e práticas de avaliação: algumas reflexões. Educação, Sociedade e Culturas, Portugal, n. 33, 2011.

BERLINER, D.; BRIDDLE, B. The manufactured crisis: myths, fraud and the attack on America’s public schools. Cambridge/Massachusetts: Perseus Books, 1995.

BRESSER PEREIRA, L. C. Reflexões sobre a reforma gerencial brasileira de 1995. Revista do Serviço Público, v. 50, n. 4, p. 5-30, 1999. 
BRITTO, T.F. O que é que a Finlândia tem? Notas sobre um sistema educacional de alto desempenho. Textos para Discussão, Brasília, n. 129, 2013. 21 p. Disponível em: $\leq$ http:// www12.senado.gov.br/publicacoes/estudos-legislativos/homeestudoslegislativos $>$. Acesso em: 15 fev. 2017.

CASTRO, M.H.G. Entrevista: Maria Helena Guimarães: "Há um tédio generalizado entre os alunos do ensino médio". Texto de Beatriz Morrone e edição de Flávia Yuri Oshima. Época, 10 ago. 2016. Disponível em: <http://epoca.globo.com/ideias/noticia/2016/08/ maria-helena-guimaraes-ha-um-tedio-generalizado-entre-os-alunos-do-ensino-medio. $\underline{\mathrm{html}>}$. Acesso em: 12 ago. 2016.

CIAVATTA-FRANCO, M. Quando nós somos o outro: questóes teórico-metodológicas sobre os estudos comparados. Educação \& Sociedade, ano XXI, n. 72, p. 197-230, ago. 2000.

COMISSÃO EUROPEIA. The Structure of the European Education Systems 2015/16: Schematic Diagrams. Eurydice Facts and Figures. Luxembourg: Publications Office of the European Union, 2015.

COUNCIL OF THE EUROPEAN COMMUNITIES. Detailed work programme the follow-up of the objectives of the education and training systems in Europe. Brussels: Office for Official Publications, 2002.

COWEN, R. Antes e Agora: Idéias, Unidade e Educação Comparada. In: COWEN, R.; KAZAMIAS, A.; ULTERHALTER, E. (Orgs.). Educaçâo comparada: panorama internacional e perspectivas. Brasília: Unesco-Capes, 2012. v. 1. p. 740-770.

. El Sistema Educativo Inglés. In: RAVENTÓS, F. (Org.). Los Sistemas Educativos Europeos: crisis o transformación? Madri: Fundación "La Caixa", 2005. p. 66-81. (Colección Estudios Sociales).

DALE, R. Globalisation and education: demonstrating a "common world educational culture" or locating a "globally strutured educational agenda"? Educational Theory, v. 50, n. 4, p. 427-448, 2000.

DEPARTAMENTO INTERSINDICAL DE ESTATÍSTICA E ESTUDOS SOCIOECONÔMICOS (DIEESE). Anuário de Sistema Público de Emprego, Trabalho e Renda. Juventude: livro 6. Slivro 6, 2015.

DURIEZ, B.; ION, J.; PINÇON, M.; PINÇON-CHARLOT, M. Institutions, statiques et nomenclatures socio-professionnelles. Essai comparitif: Royaume-Uni, Espagne, France. Revue Française de Sociologie, n. XXXII, p. 29-59, 1991.

EPSTEIN, E.H. Principales corrientes epistemológicas de educación comparada. In: TELLO, C. (Coord.). Epistemologías de la politica educativa: posicionamientos, perspectivas y enfoques. Campinas: Mercado de Letras, 2013. p. 541-552.

FREITAS, L.C. Três teses sobre as reformas empresariais na educação: perdendo a ingenuidade. Caderno CEDES, v. 36, n. 99, p. 137-144, maio-ago. 2016.

FRIGOTTO, G. Reforma de ensino médio do (des)governo de turno: decreta-se uma escola para os ricos e outra para os pobres. ANPED na Rede, 22 set. 2016. Disponível em: $\leq$ http://www.anped.org.br/news/reforma-de-ensino-medio-do-des-governo-de-turnodecreta-se-uma-escola-para-os-ricos-e-outra>. Acesso em: 10 mar. 2017. 
FRIGOTTO, G.; CIAVATTA, M. Educação básica no Brasil na década de 1990: subordinação ativa e consentida à lógica do mercado. Educação e Sociedade, v. 24, n. 82, p. 93-130, 2003.

GIROTTO, E. Sobre a hipocrisia da Reforma do Ensino Médio (ou quanto vale uma boa refeição). In: SEMINÁRIO DE FORMAÇÃO POLÍTICA DO SINTEPP, 1., Marabá, PA. Anais... 2017.8 p.

GOROSTIAGA, J.M. Um abordaje de la questión epistemológica em los estúdios comparados sobre política educativa. In: TELLO, C. (Coord.). Epistemologías de la politica educativa: posicionamientos, perspctivas y enfoques. Campinas: Mercado de Letras, 2013. p. 239-267.

HALL, D.; GUNTER, H. A nova gestão pública na Inglaterra: a permanente instabilidade da reforma neoliberal. Educação e Sociedade, Campinas, v. 36, n. 132, p. 743-758, jul.-set. 2015.

HELENE, O. Considere estes países. Correio da Cidadania, 4 jun. 2012. Disponível em: <http://blogolitica.blogspot.com.br/2012/06/considere-estes-paises.html>. Acesso em: 10 jan. 2017.

HUDDLESTON, P.; RAINBIRD, H. Vers une désarticulation entre l'éducation et le travail? Les changements de frontières entre l'éducation, la formation et l'apprentssage continue en Grande-Bretagne. In: MAROY, C.; DORAY, P. Les relations entre économie et éducation: vers de nouvelles régulations? Paris: l'Harmattan, 2003. p. 117-138.

INTERCÂMBIO, INFORMAÇÃO, ESTUDOS E PESQUISAS (IIEP); GP TRABALHO E EDUCAÇÃO DA FEUSP. Politicas Públicas de Educação e Trabalho na perspectiva dos direitos sociais. Relatório: Oficina Nacional de Educação e Trabalho. São Paulo: IIEP, 2011. 25 p.

MAROY, C.; DORAY, P. Conclusions. Quelques interrogations transversales. In: . Les relations entre économie et education: vers de nouvelle regulations? Paris: L'Harmattan, 2003. p. 291-302.

MORAES, C.S.V. Educação Permanente: direito de cidadania, responsabilidade do Estado. Trabalho, Educação e Saúde, v. 4, n. 2, p. 395-416, 2006.

Política e formação profissional no Brasil e em alguns países europeus. In: IV ENCONTRO NACIONAL DA ASSOCIAÇÃO BRASILEIRA DE ESTUDOS DO TRABALHO/ABET, 4., São Paulo, 1995. Anais... São Paulo: ABET, 1995. p. 28-29.

MORAES, R. Short-term higher education: the United States' Community Colleges' experience. Cadernos de Pesquisa, v. 44, p. 451-464, 2014. Disponível em: <http://www. scielo.br/pdf/cp/v44n152/en 11.pdf>. Acesso em: 05 mar. 2017.

NÓVOA, A. Modeles d'Analyse em Éducation Comparée: la Champ e la Carte. In: . Histoire et Comparaison (Essais sur l'Éducation). Lisboa: Educ, 1998.

NYYSSÖNEN, H. Finland's success: politics without resistance? Estudios Internacionales, año 41, n. 161, p. 35-51, set.-dez. 2008. Disponível em: <http://www.jstor.org/ stable/41391988? seq=1\#page scan tab contents $>$. Acesso em: 29 mar. 2017. 
OLIVEIRA, D.A. Nova gestão pública e governos democrático-populares. Contradições entre a busca da eficiência e a ampliação do direito à educação. Educação e Sociedade, Campinas, v. 36, n. 132, p. 625-646, jul.-set. 2015.

ORGANIZAÇÃO DAS NAÇÕES UNIDAS PARA A EDUCAÇÃO, A CIÊNCIA E A CULTURA (UNESCO); CONSELHO NACIONAL DE EDUCAÇÃO (CNE). A Qualidade Social da Educação Brasileira nos Referenciais de Compromisso do Plano e do Sistema Nacional de Educação. São Paulo: Unesco/CNE, 2015.

ORGANIZAÇÃO PARA A COOPERAÇÃO E DESENVOLVIMENTO (OCDE). Études économiques de l'OCDE: Brésil. Paris: OCDE, 2015. 30 p.

. Panorama de la societé 2016: leus indicateurs sociaux de l'OCDE. Um éclairage sur les jeunes. Paris: OCDE, 2017. 147 p.

PASIAS, G.; ROUSSAKIS, Y. Por um panóptico europeu: discursos e políticas da EU sobre educação e treinamento, 1992-2007. In: COWEN, R.; KAZAMIAS, A. (Orgs.). Educação Comparada: panorama internacional e perspectivas. Brasília: Unesco, Capes, 2012. v. 1. p. 583-602.

RANTANEN, M. O sistema de ensino finlandês: os pilares de uma sociedade baseada no conhecimento. In: BRASIL. Mundo Afora: Educação Básica e Ensino Médio. Brasília: Ministério das Relações Exteriores, 2004. p. 290-308.

SALLUN JR., B. Metamorfoses do Estado brasileiro no final do século XX. Revista Brasileira de Ciências Sociais, v. 18, n. 52, p. 53-54, 2003.

SANTAMARIA, F.S. Raventós. La crisis de los sistemas educativos europeos. In: PRATS, J.; RAVENTÓS, F. (Orgs.). Los Sistemas Educativos Europeos: ¿Crisis o transformación? Madri: Fundación "La Caixa”, 2005. (Colección Estudios Sociales). p. 5-28.

SIMÓES, C.A. Vozes Dissonantes no Ensino Médio. Impresso, 2016. 8 p.

VELOSO, J.R.P.; RODRIGUES, M.M.A. Sistemas internacionais de aprendizagem profissional: uma análise comparativa em alguns países desenvolvidos e emergentes. Boletim Técnico do Senac, v. 42, n. 1, p. 6-29, jan.-abr. 2016.

YOUNG, M. Por que o conhecimento é importante para as escolas no século XXI? Cadernos de Pesquisa, São Paulo, v. 46, n. 159, p. 18-37, jan.-mar. 2016.

Recebido em 27 de março de 2017.

Aceito em 23 de abril de 2017. 